\title{
Characterization of the atmospheric boundary layer from radiosonde observations along eastern end of monsoon trough of India
}

\author{
Sagarika Chandra $^{1}$, Arun K Dwivedi ${ }^{1, *}$ and Manoj Kumar ${ }^{2}$ \\ ${ }^{1}$ Centre of Excellence in Climatology, Birla Institute of Technology Mesra, Ranchi 835 215, India. \\ ${ }^{2}$ Centre for Environmental Sciences, Central University of Jharkhand, Ranchi 835 205, India. \\ *Corresponding author. e-mail: akdwivedi30@yahoo.com
}

In this paper, a comparison of two methods for the calculation of the height of atmospheric boundary layer (ABL), using balloon-borne GPS radiosonde data is presented. ABL has been characterized using vertical profiles of meteorological parameter. The gradient of virtual potential temperature $\left(\theta_{v}\right)$ profile for the determination of mixed layer heights (MLH) and the mean value of turbulent flow depth (TFD) obtained from the vertical profile of Bulk Richardson Number $\left(R_{i B}\right)$ have been used in this study. Oneyear data have been used for the study. There is large seasonal variability in MLH with a peak in the summer and winter whereas the TFD remained steady throughout the year. Results from the present study indicate that the magnitudes of TFD are often larger than the MLH.

\section{Introduction}

The lowest layer of the atmosphere is called troposphere. The troposphere can be divided into two parts: ABL (extending upward from the surface to a height that ranges from 100 to $3000 \mathrm{~m}$ ) and the free atmosphere (Stull 1988). The Earth's surface has a direct impact on the ABL. The ABL responds to some forcings such as frictional drag, solar heating, and evapotranspiration with a timescale of an hour or less. These forcings generate turbulence of various-sized eddies. Solar heating of the ground on a sunny day creates thermals of warmer air that rise over colder air causing vertical mixing and turbulence. Therefore, the ABL must be parameterized as a mechanism for turbulence in any weather prediction model.

The ABL height varies in time and space, ranging from hundreds of meters to a few kilometres. It is a key parameter in the description of vertical processes in the lower troposphere. The diurnal cycle of the ABL height strongly determines the environmental state at the surface over the day. It is also an important input parameter for different atmospheric models. Thus, observations of the ABL height with high vertical and temporal resolution are desirable. The top height of the ABL can be determined from vertical profiles of temperature, humidity, wind, and pollutants such as aerosol particles. These profiles can be derived from different instruments such as radiosonde, radio acoustic sounding system (RASS), wind profiler (Angevine et al. 1998), ceilometers (Eresmaa et al. 2006), lidar (Hennemuth and Lammert 2006) and sodar (Russell and Uthe 1978). All these instruments have restrictions concerning weather conditions, spatial and temporal resolution, and accuracy.

For the determination of ABL height, various techniques have been suggested. Here, we use high-resolution upper air meteorological data

Keywords. Boundary layer; GPS sonde; mixed layer height; turbulent flow depth. 
obtained through GPS radiosonde. The present study attempts to find the characteristics of ABL over Ranchi, India using more than one-year (20102011) database. This work focuses on the study of large-scale monsoonal circulation on the ABL processes. The objectives of this paper are:

- to study the ABL processes for the determination of mixed layer height (MLH) and turbulent flow depth (TFD) and also

- to analyse ABL height variation during different seasons over Ranchi.

\section{Background of meteorological conditions}

The experimental site, BIT Mesra, Ranchi $\left(23^{\circ} 45^{\prime} \mathrm{N}, 85^{\circ} 43^{\prime} \mathrm{E}\right)$ which has wet convective conditions is located near the eastern end of the monsoon trough. The site has a barren land with erratic dry grass. A dense boundary of trees exists in the east to southeast of the site at a distance of about $200 \mathrm{~m}$. The river Subernarekha lies in the east to southwest direction to the site and there is residential area to the north. The location map is shown in figure 1. Ranchi lies in a humid subtropical monsoon area of India with generally hot summers from March to May and well distributed rainfall during the southwest (SW) monsoon from June to September. The normal annual rainfall is $\sim 1394 \mathrm{~mm}$. Maximum rainfall has been observed during June to September. About $80 \%$ of the total annual rainfall is received during this monsoon period. Winters are marked by dry and cold weather from December to February. January is the coldest month with the mean daily

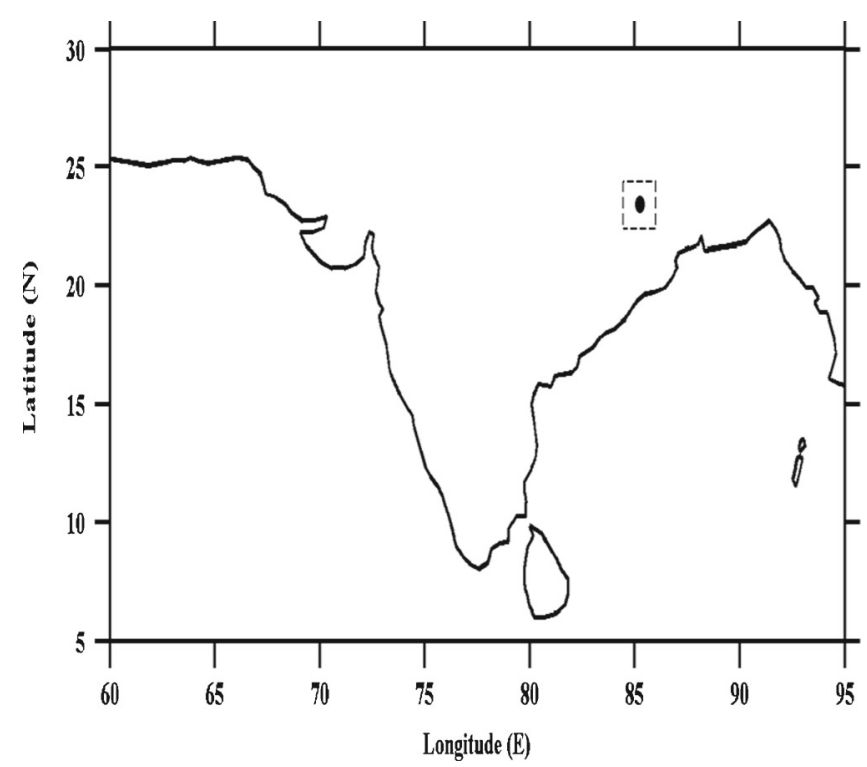

Figure 1. Location of Ranchi. maximum temperature at $22^{\circ} \mathrm{C}$ and the mean daily minimum temperature at $7^{\circ} \mathrm{C}$, the hottest month of the year being May with maximum temperature at $36^{\circ} \mathrm{C}$. In general, the meteorological conditions over the year can be classified into four categories: (1) summer (March-May), (2) monsoon (June-September), (3) post-monsoon (OctoberNovember), (4) winter (December-February).

The meteorological conditions over this area are influenced by the mean characteristics of atmospheric pattern. To show the mean wind circulation pattern at $850 \mathrm{hPa}$ over Ranchi during different seasons, the MDISC data subset of NASA Earth Data has been used. Figure $2(\mathrm{a}-\mathrm{d})$ shows seasonal average of wind circulation pattern for the summer, monsoon, post-monsoon, and winter respectively. Generally, the surface layer wind speed over Ranchi remains below $4 \mathrm{~m} / \mathrm{s}$ during the summer and the direction of winds are westerly which is shown in figure 2(a). In monsoon season, wind speed is very high up to $7-9 \mathrm{~m} / \mathrm{s}$. When the convective activities develop from the surface layer, the area receives thunderstorm and rain. During monsoon period, this part of India receives a good amount of rain with frequent precipitation. This part of India lies near the eastern end of monsoon trough.

In comparison to the monsoon, the magnitudes of wind decrease gradually up to $2-3 \mathrm{~m} / \mathrm{s}$ in the post-monsoon season. From post-monsoon season to winter season the wind becomes calm and dry. The circulation of wind becomes northeasterly and sometimes northerly in this season. Thus the wind pattern is completely continental over this region in this period, which is shown in figure 2 (c and d). The cold and dry northeasterly winds prevail over this region making its convective activity insignificant.

\section{Data and methods}

In this study, upper air meteorological observations have been used which were obtained through indigenously developed GPS radiosonde (referred to as Pisharoty Sonde, as named by the manufacturers). These observations have been used for the determination of the ABL height over Ranchi. (table 1 provides some of the details on accuracies and response time of different sensors used in Pisharoty Sondes). The balloon-borne Pisharoty Sondes was launched at $1430 \mathrm{hrs}$ local time in Ranchi as a part of routine meteorological observations of Space Physics Laboratory, VSSC, ISRO. A total of 97 good soundings data has been taken between January 2011 and December 2011 for the study. A limitation of the study is that it is based on a small sample of data. 

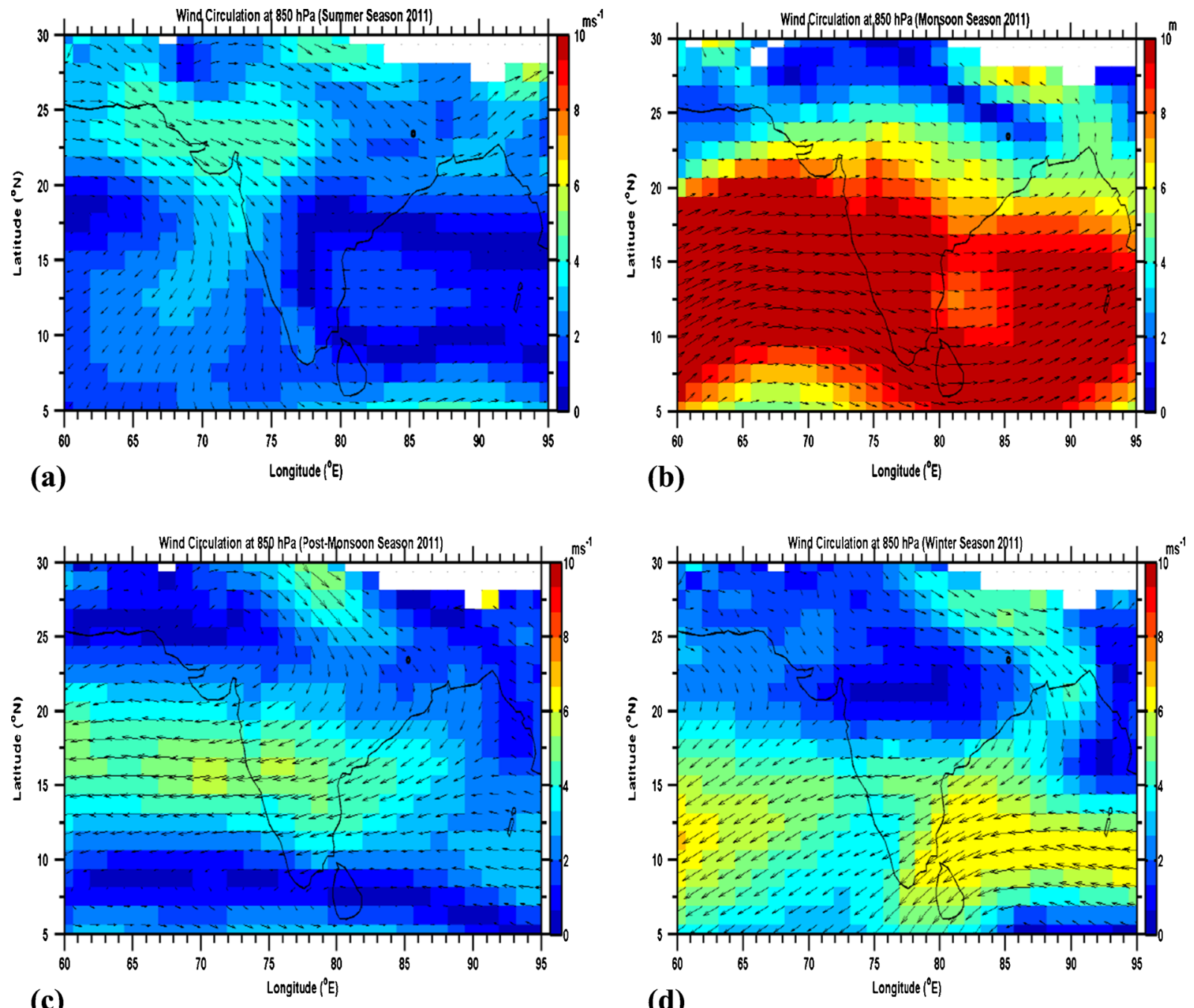

(d)

Figure 2. Seasonally averaged wind circulation corresponding to $850 \mathrm{hPa}$ from NASA Earth data, MDSCI data subset for (a) summer (March, April, May), (b) monsoon (June, July, August, September), (c) post-monsoon (October, November) and (d) winter (December, January, February).

Table 1. Technical details of Pisharoty GPS sondes.

\begin{tabular}{lccc}
\hline Name of the sensor (measured parameter) & Range & Response & time \\
\hline Platinum RTD (air temperature) & $-200^{\circ}-400^{\circ} \mathrm{C}$ & $<2 \mathrm{~s}$ & $\pm 0.1^{\circ} \mathrm{C}$ \\
Capacitive humidity sensor (relative humidity) & $0-100 \%$ & $<4 \mathrm{~s}$ & $\pm 1.5 \%$ \\
MEMS sensor (atmospheric pressure) & $5-1000 \mathrm{hPa}$ & $2 \mathrm{~s}$ & $\pm 2 \% \mathrm{span}$ \\
\hline
\end{tabular}

\subsection{Data processing and quality checks}

As a part of the quality control, it is essential to remove the bad data points that occurred due to failure of electronic components of the instruments, voltage fluctuations or due to the manual interference during the experiments. The raw data collected from the Pisharoty Sondes consist of pressure, temperature, relative humidity, and geographical position of the balloon in terms of its latitude, longitude, and altitude.

- All the values including the measurements corresponding to the descent phase of the balloon are rejected.

- The vertical profiles of meteorological parameters are smoothened through moving average technique and all data are arranged at regular intervals of $10 \mathrm{~m}$ in vertical. 
- After arrangement of all the meteorological parameters to regular intervals, virtual potential temperature $\left(\theta_{v}\right)$ and bulk Richardson number $\left(R_{i B}\right)$ are derived.

- Our analysis of all the profiles was confined to an altitude of $5000 \mathrm{~m}$.

\subsection{Method of analysis}

In general, the $\mathrm{ABL}$ over a given region can be classified into different layers depending on the amount of moisture present in the lower atmosphere and wind circulation over the area, since the wind and temperature play major roles in the classification of the two different sublayers such as:

(i) Mixed layer: The mixed layer height (MLH), a type of boundary layer, is the height up to which turbulent vertical mixing processes dissipate the atmospheric properties (such as wind speed and moisture) or substances originating from the surface. It is usually flatter than the boundary layer, but fills the whole ABL in the deep convective boundary layers.

(ii) Turbulent flow: It is a fluid dynamic concept, where the turbulent flow is distinguished from the laminar flow. The turbulent flow depth (TFD) is the level of turbulence, which can be derived from the fluctuation of wind components or from the temperature fluctuations. The TFD can be taken as the critical threshold value of Richardson number.

To study the apparent interconnection between these two stratified layers, two standard methods have been used as discussed below.

\subsubsection{Gradient method}

The vertical profile of temperature and wind in the lower part of the troposphere has often been used for a subjective estimation of the mixed layer (Seibert et al. 2000). There are different gradient methods available for the estimation of the mixed layer under convective conditions, which are as follows:

- The 'Parcel Method' (Holzworth 1964; Seibert et al. 2000), in which a mixing height is evaluated by comparing the surface value of virtual potential temperature $\left(\theta_{v}\right)$ to values higher than that. The height at which $\theta_{v}$ is same as the surface value, an indeterminate parcel of air (lifted from the surface) would be in symmetry with its environment. The resulting ABL height is often called the 'mixing height'.
In this regard, virtual potential temperature $\left(\theta_{v}\right)$ happens to be a very useful thermodynamic parameter (Subrahamanyam and Ramachandran 2003) for representation of the mixed layer and can be estimated using the following equations:

$$
\theta=T\left(\frac{1000}{P}\right)^{0.286}
$$

$$
\theta_{V}=\theta(1+0.61 \cdot r)
$$

where $\theta$ represents the potential temperature (K), $T$ represents the temperature $(\mathrm{K}), P$ represents the air pressure (mbar) and $r$ represents mixing ratio $(\mathrm{g} / \mathrm{kg})$.

- The level of the maximum vertical gradient of potential temperature $(\theta)$ (Stull 1988; Oke 1988; Ao et al. 2008); characteristic of a transformation of a convectively less stable region below to a more stable region above.

- The base of the elevated temperature $(T)$ inversion; not all soundings have elevated inversion, but when present, the base serves as the cap to mixing below and so can be considered as the ABL height (Seibert et al. 2000; Ao et al. 2008).

- The level of the minimum vertical gradient of the specific humidity (q) (Ao et al. 2008).

- The level of the minimum vertical gradient of relative humidity $(\mathrm{RH})$.

Among the above gradient methods, the virtual potential temperature gradient method was taken into consideration for our study.

\subsubsection{Bulk Richardson number $\left(R_{i B}\right)$ method}

The bulk Richardson number $\left(R_{i B}\right)$ is a dimensionless number in meteorology, which relates vertical stability and vertical shear. It provides a measure of the dynamic stability of a flow, which is given by the following expression for an altitude $z$ as:

$$
R_{i B}=\frac{g\left(\frac{\partial \theta_{V}}{\partial z}\right)}{\bar{\theta}_{V}\left[\left(\frac{\partial u}{\partial z}\right)^{2}+\left(\frac{\partial v}{\partial z}\right)^{2}\right]}
$$

where $\left(\partial \theta_{V} / \partial z\right),(\partial u / \partial z)$ and $(\partial v / \partial z)$ are the gradients in virtual potential temperature $\left(\theta_{V}\right)$ and the zonal and meridional components $(u, v)$ of winds respectively. The term $\left(\bar{\theta}_{V}\right)$ represents the mean of virtual potential temperature for the two levels; $g$ is the acceleration due to gravity. A value of 0.25 is the critical value of $R_{i B}$ above which the turbulent flow becomes the laminar flow (Sørensen 1998). In this study, we use 0.25 as the critical value of $R_{i B}$ for the demarcation of the TFD. The same method has been used to determine the 
variability of MLH and TFD over Thiruvananthapuram by Sandhya et al. (2011).

\section{Result and discussion}

The MLH and TFD determined by gradient method and bulk Richardson number method respectively, are shown in figure 3 . The monthly mean of MLH and TFD has been shown in figure 4 and their standard deviation for each month is shown as the error bars. The details of the total number of observations, used for deriving these histograms have been shown in table 2. During June to September there is less wind circulation and sometimes heavy rain due to the active monsoon. Therefore, the MLH is less in this period as shown in the histogram for these particular months (figure 4).

Figure 4 shows that the magnitudes of MLH are less than that of TFD. It indicates the dominant role of turbulence in ABL dynamics over Ranchi after winter season. The MLH variations were recorded in the range of 787-2457.15 m with a mean of $1386 \mathrm{~m}$, whereas TFD showed variations in the range of $1250-1983 \mathrm{~m}$ with the mean of $1646.4 \mathrm{~m}$. The magnitude of MLH is quite close to the TFD in the summer season due to the high fluctuation of wind speed and temperature. In the monsoon and post-monsoon season, the thickness
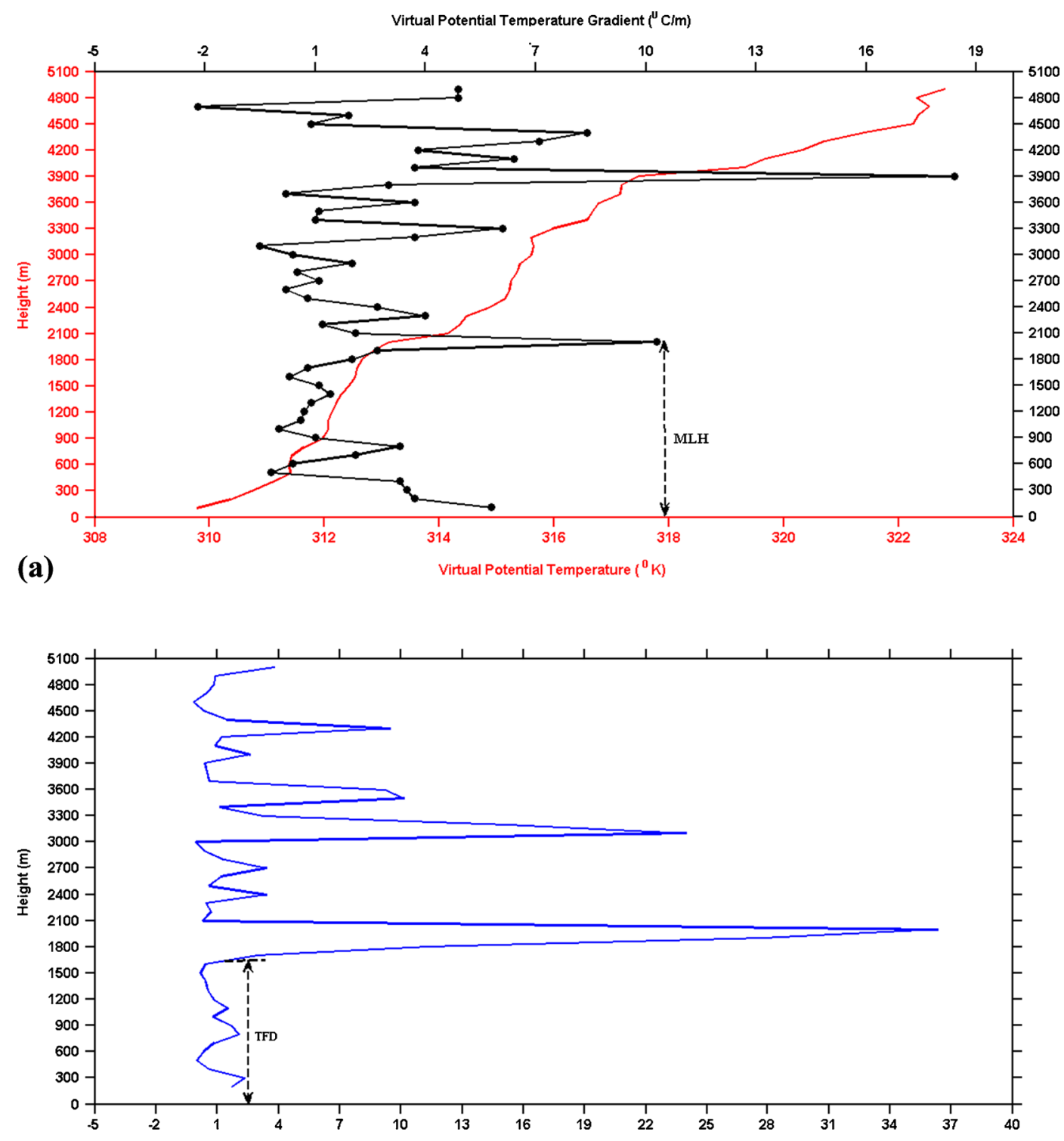

(b)

Figure 3. Vertical profiles of (a) virtual potential temperature $\left(\theta_{v}\right)$ and $\left(\partial \theta_{V} / \partial z\right)$ and (b) bulk Richardson number $\left(R_{i B}\right)$ representing two different techniques assumed for the determination of mixed layer height (MLH), turbulent flow depth (TFD) respectively. These layers are marked by arrows in the figure. 
Table 2. Statistics on the availability of Pisharoty Sonde data.

\begin{tabular}{llcc}
\hline Season & Month & $\begin{array}{c}\text { No. of } \\
\text { soundings }\end{array}$ & $\begin{array}{c}\text { Total no. of } \\
\text { soundings }\end{array}$ \\
\hline Summer & March & 10 & 22 \\
& April & 6 & \\
May & 6 & 31 \\
& June & 9 & \\
& July & 7 & \\
Post-monsoon & August & 9 & 18 \\
& September & 6 & \\
Winter & October & 6 & \\
& November & 12 & \\
& December & 10 & 97 \\
\hline \multirow{2}{*}{ Complete year } & January & 8 & \\
\hline
\end{tabular}

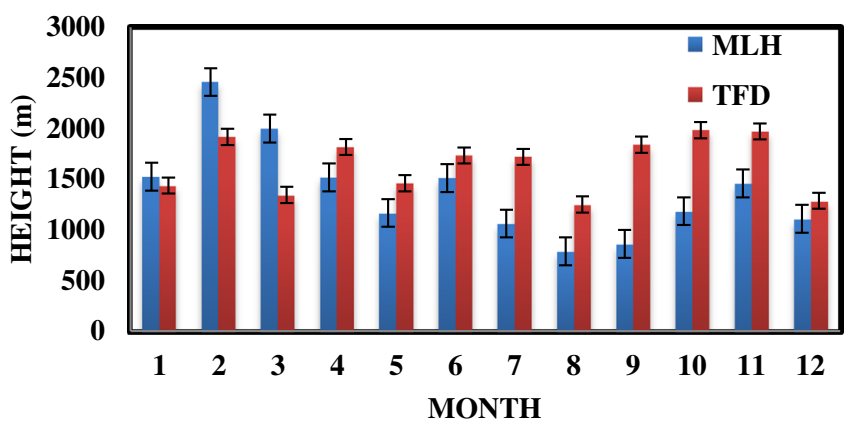

Figure 4. Monthly variations in mixed layer height (MLH) and turbulent flow depth (TFD) shown as histograms. Error bars associated with these parameters indicate the derivations for each month.

of turbulent flow is found to be almost two times that of mixed layer. This can attribute to the fact that the lower atmosphere generally experiences high wind speed and high turbulence during this season.

In figure 5, we show the seasonal variations in MLH and TFD by grouping the entire database to respective seasons. The error bars associated with these parameters indicate their standard deviations for the season. The MLH variations are found in the range of 1055-1697 $\mathrm{m}$, with a large value during summer season. In contrast to this, the MLH exhibits relatively lower value during the monsoon as an indication of suppressed convection in this season. This is due to the cloud in the atmosphere and the availability of moisture content in the prevailing wind within the boundary layer. The virtual potential temperature is constant in the lower height so that the air parcels are not moving upward and the convection is suppressed. Turbulence is also maximum in the lower atmosphere and due to the high turbulent vertical mixing processes,

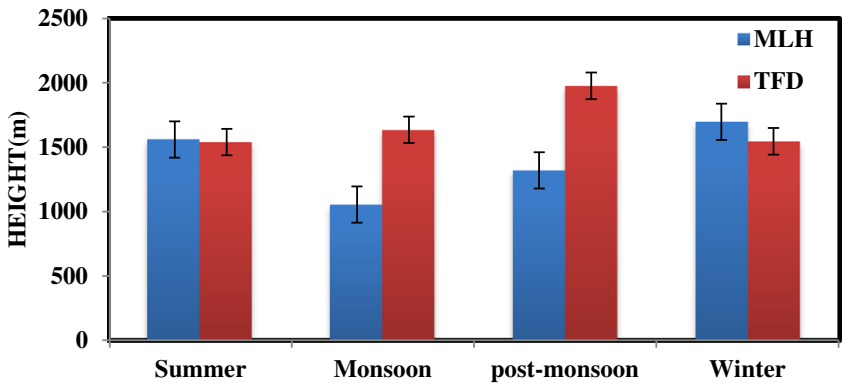

Figure 5. Seasonal variations in mixed layer height (MLH) and turbulent flow depth (TFD) shown as histograms. Errors bars associated with these parameters indicate the standard deviations for each season.

the value of TFD is quite large in comparison to MLH in monsoon season. During the post-monsoon season, the magnitude of MLH is observed to be quite larger than that of monsoon season (almost 1.2 times larger than monsoon season). The specific humidity in monsoon season is observed $\sim 2.3$ times larger than that in the post-monsoon season. The value of MLH ranges between 1540 and 1976.5 $\mathrm{m}$ with a mean of $1758.2 \mathrm{~m}$, reaches its peak in the winter season due to the dry weather condition and the specific humidity is less during this season. In this season, wind pattern is completely dry and continental. The specific humidity also plays a very important role in the variation of MLH during monsoon to winter. The value of specific humidity is larger in monsoon than in summer and winter. Significant seasonal variations have been observed in the magnitude of TFD and MLH. The magnitude of TFD is much higher than that of MLH in the monsoon and the post-monsoon seasons, while the value of MLH is higher than that of TFD in winter and summer seasons. It is interesting to note that Srivastava et al. (2010) have shown the variability of MLH over Ahmedabad, one of the tropical urban sites in India. There are very small variations observed during the winter while there is large variability during pre-monsoon and monsoon seasons. Sandhya et al. (2011) have shown the variability of MLH and TFD over Thiruvanathapuram, one of the coastal sites in India. They adopt the same techniques for the quantification of $\mathrm{MLH}$ and TFD. In their region, the magnitudes of MLH were always larger than those of TFD. In comparison to the above studies, there is large variation of MLH and TFD observed over this region, which has been discussed in the concluding part.

There are only two synoptic systems over the region (17-23 June and 19-20 October) during which we have a GPS sonde observation. A deep depression developed over Bay of Bengal on 16th June 2011. It then continued its northward movement for some time, then moved westnorthwestwards across Gangetic West Bengal, 
Jharkhand, north Chhattisgarh and west Madhya Pradesh during 17-23 June and weakened gradually. It weakened into a well-marked low-pressure area on 23rd June over west Madhya Pradesh. It brought southwest monsoon over eastern and central India and caused excess rainfall over these regions. A deep depression formed over the northeast Bay of Bengal on 19th October 2011 morning. Moving northeastwards, it crossed the Bangladesh coast. Convective cloud cluster developed over southeast and adjoining east central Arabian Sea during the last week of October 2011. It gradually concentrated into a low-pressure area on 27th October, 2011. It became well marked, while moving west-northwestwards on 28th October and concentrated into a depression over west central and adjoining southwest Arabian Sea and lay centered at 0600 UTC on 29th October 2011. Not all the above systems affected our region.

We investigated TFD and MLH during these two synoptic system days using these observations and compared them with nonsynoptic system day's values. These synoptic events occurred in monsoon and post-monsoon season respectively as stated above. We have GPS sonde data on 20 June, 22 June, and on 19 October. The comparison of TFD and MLH during the synoptic and non-synoptic days has been presented in figure 6 . In the case of synoptic days, the magnitude of MLH is significantly larger than that of TFD. This could be because of less wind shear available during these events, which is responsible for TFD. The
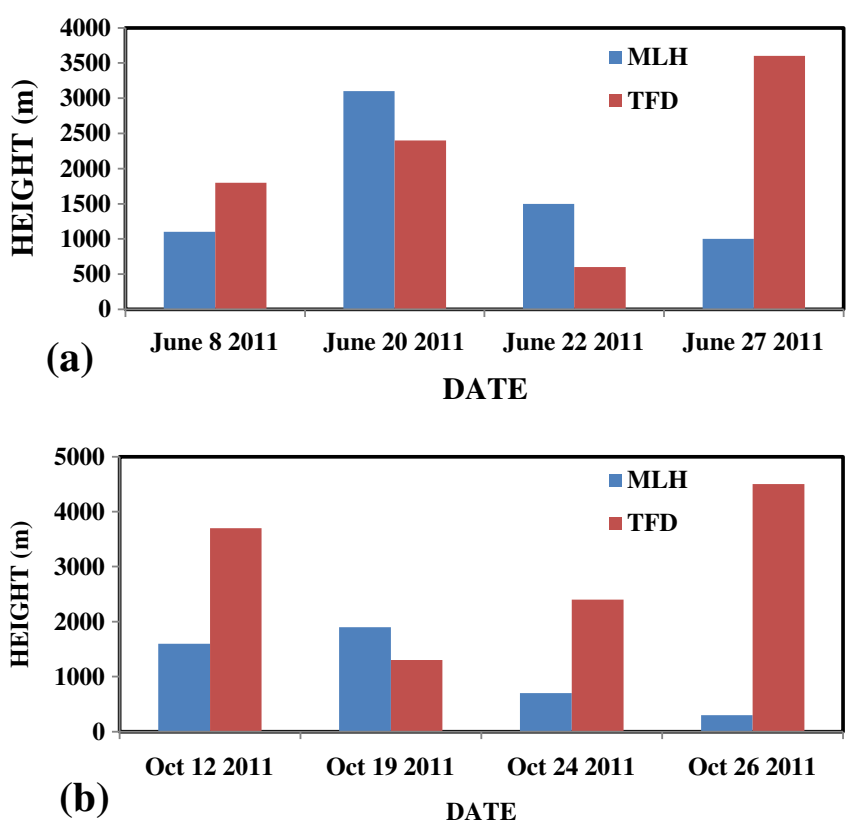

Figure 6. Comparison of MLH and TFD in synoptic and non-synoptic days during (a) monsoon and (b) postmonsoon seasons. non-synoptic days have been taken just before and after the synoptic days.

\section{Conclusion}

In this paper, we made use of upper air meteorological observations for a period of more than one year obtained from balloon-borne Pisharoty Sondes over Ranchi (an inland station), for characterization of the vertical structure of the ABL. Two different techniques were adopted for quantification of mixed layer heights and turbulent flow depth. The important findings are shown below:

- Mixed layer height (MLH) evaluated through $\theta_{v}$ gradient method showed variations within the range of $787-2457.15 \mathrm{~m}$ with a mean of $1386 \mathrm{~m}$, whereas the turbulent flow depth (TFD) determined through $R_{i B}$ varied between 1250 and $1983 \mathrm{~m}$ with the mean of $1646.4 \mathrm{~m}$. The magnitudes of TFD were larger than those of the MLH.

- Irrespective of comprehensive seasons, the magnitudes of TFD remained steady throughout the year, whereas the MLH showed large variability with typical peak in the winter to summer.

- Due to the strong influence of the wind circulation during the summer season, formation of the thermal internal boundary layer was distinguished over the study area which is not clear in the monsoon season.

- During the monsoon period, the temperature and pressure fluctuate very much and also the high moisture content and suppressed convection present in the atmosphere cause MLH to be comparatively less.

\section{Acknowledgements}

The authors gratefully acknowledge the SPL, VSSC, ISRO for their logistical and technical support in smooth functioning of balloon borne GPS ascents for the study under ISRO (IGBP)-NOBLE project. Sagarika Chandra is thankful to the Birla Institute of Technology for sponsoring a fellowship for her PhD research work.

\section{References}

Angevine Wayne M, Bakwin Peter S and Davis Kenneth J 1998 Wind profiler and RASS measurements compared with measurements from a 450-m tall tower; J. Atmos. Oceanic Technol. 15 818-825.

Ao C O et al. 2008 Planetary boundary layer information from GPS radio occultation measurements; GRAS SAF Workshop on Applications of GPSRO Measurements, 
16-18 June 2008, pp. 123-131 (http://www.grassaf.org/ Workshops/agrom_prog/Ao.pdf).

Eresmaa N et al. 2006 Mixing height determination by ceilometers; Atmos. Chem. Phys. 6 1485-1493.

Hennemuth B and Lammert A 2006 Determination of the atmospheric boundary layer height from radiosonde and lidar backscatter; Bound.-Layer Meteorol. 1 181-200, doi: 10.1007/s10546-005-9035-3.

Holzworth G C 1964 Estimates of mean maximum mixing depths in the contiguous United States; Mon. Wea. Rev. 92 235-242.

Holzworth G C 1967 Mixing depths, wind speeds and air pollution potential for selected locations in the United States; J. Appl. Meteorol. 6 1039-1044.

Nair Sandhya K et al. 2011 Characterization of the Vertical Structure of Coastal Atmospheric Boundary Layer over Thumba $\left(8.5^{\circ} \mathrm{N}, 76.9^{\circ} \mathrm{E}\right)$ during Different Seasons; Hindawi Publishing Corporation Advances in Meteorology Volume, Article ID 390826, doi: 10.1155/2011/390826.

Oke T R 1988 Boundary Layer Climates; Halsted Press, New York, 435p.

Russell Philip B and Uthe Edward E 1978 Regional patterns of mixing depth and stability: Sodar network measurements for input to air quality models; Bull.
Am. Meteor. Soc. 59 1275-1287, doi: 10.1175/15200477(1978)059<1275:RPOMDA>2.0.CO;2.

Seibert P, Beyrich F, Gryning S E, Joffre S, Rasmussen A and Tercier P 2000 Review and intercomparison of operational methods for the determination of the mixing height; Atmos. Environ. 34 1001-1027.

Seibert P et al. 2000 Review and intercomparison of operational methods for the determination of the mixing height; Atmos. Environ. 34 1001-1027.

Sørensen J H 1998 Sensitivity of the derma long-range Gaussian dispersion model to meteorological input and diffusion parameters; Atmos. Environ. 32 41954206.

Srivastava S et al. 2010 Seasonal variability in mixed layer height and its impact on trace gas distribution over a tropical urban site: Ahmedabad; Atmos. Res. 96 79-87.

Stull R B 1988 An Introduction to Boundary Layer Meteorology, Kluwer Academic Publishers, Dordrecht, 666p.

Subrahamanyam D B and Ramachandran R 2003 Structural characteristics of marine atmospheric boundary layer and its associated dynamics over the central Arabian Sea during INDOEX, IFP-99 campaign; Curr. Sci. 85 1334-1340. 